\title{
Sugestões brasileiras ao poeta de Mensagem: uma leitura do poema de Fernando Pessoa
}

Resumo: A leitura proposta parte do princípio de que o Modernismo português e o Modernismo brasileiro são dois momentos culturais distintos. Antes, porém, que a Mensagem de Fernando Pessoa chegasse ao Brasil, a poesia brasileira já contribuíra, pelo menos com sugestôes temáticas, para a feitura do pequeno grande livro do poeta português: Mensagem. Procura-se mostrar que Fernando Pessoa aceitou a contribuição, que não lhe chegou através do nosso Modernismo, mas pela poesia de um dos nossos melhores parnasianos: Olavo Bilac. Revê-se confronto intertextual feito em 1966, por Ariano Suassuna. Pretende-se, mais, divulgar precioso ensaio de literatura comparada assinado pelo autor de A pedra do Reino, para que seja ele admirado não apenas como teatrólogo e romancista. No teatro e no romance, basta sua obra para o consagrar.

Palavras-chave: Mensagem, Fernando Pessoa, Olavo Bilac, Ariano Suassuna.

Encontros e desencontros marcam a história do Modernismo brasileiro, considerado em relação com a história do Modernismo português. Estudos de literatura comparada revelam este fato e mostram que raros e acidentais foram os pontos de encontro havidos entre os dois modernismos, cujos participantes não se 
acharam unidos nos seus primeiros momentos, apesar da direção luso-brasileira da revista Orpheu.

Referindo-se aos primeiros modernistas brasileiros e portugueses os futuristas, como eram chamados - Mário da Silva Brito os vê "como operários que escavassem o mesmo túnel subterrâneo, partindo de pontos extremos, chegaram, a dado instante à mesma parede divisória - e não se puderam comunicar".

Ronald de Carvalho teria sido o elemento de união entre os dois grupos, pois de ambos participou. Conviveu com o simbolista Luiz de Montalvor, durante prolongada estada deste no Rio de Janeiro e dele recebeu influência literária, como observa Andrade Muricy. ${ }^{2}$ Trata-se, porém, de influência simbolista, como também simbolista é todo o espírito do vol. I de Orpheu, único de que Ronald participou. Mas nessa época - 1915 - ainda não se congregara o grupo dos brasileiros que fariam a Semana de Arte Moderna.

Não houve, pois, interinfluências entre o grupo de Orpheu e o grupo da Semana. Assinale-se que a proposta dos modernistas brasileiros preconizava declarado repúdio às sugestões europeias, notadamente lusitanas, o que levou o Modernismo brasileiro a reviver, embora menos apaixonadamente, posição antilusitanista semelhante àquela que anteriormente o Romantismo sustentara no Brasil. Certamente o lusofobismo dos românticos terá contribuído para que o Modernismo português e o Modernismo brasileiro fossem movimentos culturais entre si mesmos distanciados.

Isto posto, tentemos uma leitura comparativa de Fernando Pessoa. Seria de esperar que, tratando-se de poeta cuja obra é tão estudada, houvesse na sua bibliografia crítica consideráveis estudos relacionados com a questão. Muito ao contrário, na bibliografia sobre Fernando Pessoa o que se nota é a escassez de estudos comparativos que se proponham confrontar a obra literária do poeta português com alguns aspectos, por mais genéricos que sejam, da Literatura Brasileira.

O fato de Ricardo Reis ter-se expatriado para o Brasil, onde passou a viver desde 1919, não é tão significativo para se concluir seja Fernando Pessoa um poeta luso-brasileiro, como insinua Maria Aliete Dores Galhoz, que também, como os demais estudiosos da obra do poeta, não se aprofundou em análise comparativa

1. BRITO. História do modernismo brasileiro, p. 59.

2. MURICY. Panorama do movimento simbolista brasileiro, v. I, p. 56. 
que pudesse demonstrar a brasilidade de Ricardo Reis. Talvez se possa aplicar a Fernando Pessoa o mesmo que já se disse sobre Ronald de Carvalho, provavelmente o escritor brasileiro mais diretamente influenciado por Fernando Pessoa. Entretanto, se Ronald é autor de "uma poesia de supercivilizado", conforme opinião de Vinícius de Moraes, Fernando Pessoa, então, seria escritor civilizado demais para ser brasileiro.

Esta ligeira análise do texto poético de Fernando Pessoa vai concentrar-se em alguns poemas de Mensagem, livro em que o poeta "singularizase como um épico sui generis, introvertido, cantor, sem tuba ruidosa, de miríficas irrealidades", para tornar-se "intérprete comovido da História nacional", conforme observa Jacinto do Prado Coelho. ${ }^{3}$

Na Edição Aguilar (Rio de Janeiro, 1960), o livro Mensagem vem precedido de um texto em prosa de Fernando Pessoa intitulado Nota preliminar, até então inédito, que lhe serve de prefácio. Esclarece o editor que se trata de "Apontamento solto de Fernando Pessoa", onde o poeta alerta para as cinco condições seguintes, que julga essenciais ao intérprete para o entendimento dos símbolos que se propõe interpretar: simpatia, intuição, inteligência, compreensão e, finalmente, a "menos definível" dessas cinco condições, que pode ser a graça ou "a mão do superior Incógnito", ou "o Conhecimento e Conservação do Santo Anjo da Guarda”. Quanto à simpatia, explica Fernando Pessoa: "tem o intérprete que sentir simpatia pelo símbolo que se propõe interpretar. A atitude cauta, a irônica, a deslocada todas elas privam o intérprete da primeira condição para poder interpretar".

Experimentando indisfarçável simpatia pelos símbolos da história épica de Portugal, às vezes confundindo aqueles símbolos com o próprio mito, que na definição do poeta "é o nada que é tudo", Fernando Pessoa constrói os poemas de Mensagem. Todos os poemas deste pequeno livro são contaminados daquilo que Jacinto do Prado Coelho considera "interiorização da matéria épica, tão perfeitamente integrada no clima subjectivo do autor que as figuras da epopéia se transformam em suas intercessoras ou símbolos das vivências pessoais". Vai-se concretizar em Mensagem aquela profecia de difícil entendimento, já anunciada por Fernando Pessoa em 1912, em artigo publicado em A Águia:

E a nossa grande Raça partirá em busca de uma Índia nova, que não existe no espaço, em naus que são construídas daquilo de que os sonhos são feitos.

3. Coelho. Diversidade e unidade em Fernando Pessoa, p. 58 e 65. 
Já no verso inicial do primeiro poema da $2^{\underline{a}}$ parte de Mensagem, dedicado ao Infante D. Henrique, o poeta vem confirmar o mundo de sonhos antevisto em 1912:

Deus quere, o homem sonha, a obra nasce.

A Mensagem de Fernando Pessoa proclama que é preciso sonhar. Nessa perspectiva, é triste, irremediavelmente triste, o homem acomodadamente feliz, que contentar-se com a felicidade doméstica, não sonha:

Triste de quem vive em casa,

Contente em seu lar,

Sem que um sonho, no erguer de asa,

Faça até mais rubra a brasa

Da lareira a abandonar.

Aquele antigo sonho que se lê nas trovas de Bandarra é insistentemente evocado na Mensagem de Fernando Pessoa, onde o sonho há de ser sempre sonho, assim como o mito "chama-se objectivamente mito, a lenda, lenda; àquela febre de grandeza que despreza os limites dá-se o nome de loucura", como adverte Jacinto do Prado Coelho.

Se o sonho não pode deixar de ser sonho, a profecia de Bandarra, enquanto sonho, há de ter valor em si mesma, razão por que jamais se realizará. A Mensagem de Fernando Pessoa valoriza Bandarra porque Bandarra sonhou, mas não apenas porque profetizou o impossível retorno de D. Sebastião. Assim, como sonhador, Bandarra

Não foi nem santo nem herói

Mas Deus sagrou com seu sinal

Este cujo coração foi

Não português mas Portugal.

Uma coisa é o sonho de Bandarra, que Mensagem interpreta como síntese do espírito português; outra coisa, a volta impossível de D. Sebastião, jamais concebida pelo poeta de Mensagem. Dirigindo-se diretamente a D. Sebastião, Fernando Pessoa o vai encontrar lá "no fundo de não-seres", para daí convocar o malfadado Rei a assumir o novo destino que o sonho de Portugal lhe traçou: 
Onde quer que, entre sonhos e dizeres,

Jazas, remoto, sente-te sonhado,

E ergue-te do fundo de não-seres

Para teu novo fado!

Transformado em sonho, D. Sebastião já não é nem poderá voltar a ser, posto que sonho. E o poeta de Mensagem conclama o povo português para a realidade, ou seja, para crer na verdade irretorquível que é a morte de D. Sebastião, que já não é um sonho que acabou, mas uma vida que se desfez:

Quem vem viver a verdade

Que morreu D. Sebastião?

Como a indagação destes versos, termina o segundo dos poemas dedicados aos símbolos interpretados em Mensagem.

Tentemos indicar agora a gênese desse mundo de sonhos que é a Mensagem do sonhador Fernando Pessoa. Assim, as nossas considerações voltarão a ficar, se não diretamente ligadas ao tema proposto, pelo menos ao redor dele. Para tanto, tomemos versos de um poema que traz como epígrafe um texto colhido na História de Portugal, de Oliveira Martins:

Acreditavam os antigos celtas, do Guadiana espalhados até a costa, que, no templo circular do Promontório Sacro, se reuniam à noite os deuses, em misteriosas conversas com esse mar cheio de enganos e tentações.

Segue-se o poema, que vai encontrar em Sagres, solitário, mergulhado no mais profundo dos sonhos, o Infante D. Henrique, mais um símbolo da gente portuguesa, que vem assim interpretado:

Em Sagres. Ao tufão, que se desencadeia, A água negra, em cachões, se precipita, a uivar; Retorcem-se gemendo os zimbros sobre a areia... E, impassível, opondo ao mar o vulto enorme, Sob as trevas do céu, pelas trevas do mar, Berço de um mundo novo, o promontório dorme.

Só, na trágica noite e no sítio medonho, Inquieto como o mar sentindo o coração, Mais largo do que o mar sentindo o próprio sonho, 
- Só, aferrando os pés sobre um penhasco a pique, Sorvendo a ventania e espiando a escuridão,

Queda, como um fantasma, o Infante D. Henrique...

Forte, em Ceuta, ao clamor dos pífanos de guerra, Entre as mesnadas (quando a matança sem dó Dizimava a moirama e estremecia a terra), Viram-no levantar, imortal e brilhante, Entre os raios do sol, entre as nuvens do pó, A alma de Portugal no aceiro do montante.

Em Tânger, na jornada atroz do desbarato, - Duro, ensopando os pés em sangue português, Empedrado na teima e no orgulho insensato, Calmo, na confusão do horrendo desenlace, - Vira partir o irmão para as prisões de Fez, Sem um tremor na voz, sem um tremor na face.

É que o Sonho lhe traz dentro de um pensamento A alma toda cativa. A alma de um sonhador Guarda em si mesma a terra, o mar, o firmamento, E, cerrada de todo à inspiração de fora, Vive como um vulcão, cujo fogo interior A si mesmo imortal se nutre e se devora.

Tu que, casto, entre os teus sábios, Murchando a flor dos teus dias,

Sobre mapas e astrolábios

Encaneces e porfias;

Tu, buscando o oceano infindo, $\mathrm{Tu}$, apartado dos teus, (Para, dos homens fugindo, Ficar mais perto de Deus);

$\mathrm{Tu}$, no agro templo de Sagres, Ninho das naves esbeltas, Reproduzes os milagres Da idade escura dos Celtas: 
Vê como a noite está cheia

De vagas sombras... Aqui,

Deuses pisaram a areia,

Hoje pisada por ti.

Esses versos, que encontram no sonho sua ideia central, vão contemplar em Sagres o sonhador e solitário Infante, sozinho entre os homens, pra ficar mais perto de Deus.

O poema retoma e interpreta a seu modo episódios da história épica de Portugal, invocando o depoimento do historiador Oliveira Martins. Esses versos, que podem parecer do poeta português, foram escritos por Olavo Bilac. ${ }^{4}$

Que têm eles a ver com a Mensagem de Fernando Pessoa?

Quem vai responder à pergunta é um intelectual nordestino, conhecido e conceituado como dramaturgo e romancista, que através do seu movimento armorial procura resgatar as tradições da cultura popular do nordeste brasileiro. Pretende-se valorizá-lo agora como ensaísta que navega seguro nas águas da crítica literária. Busquemos, pois, a resposta no ensaio "Bilac e Fernando Pessoa - Uma presença brasileira em Mensagem", de Ariano Suassuna.

Preliminarmente, o ensaísta observa que crítica literária não é sua especialidade. A seguir, propõe-se mostrar que o livro Mensagem, de Fernando Pessoa, teve no poema "Sagres", de Bilac, dentre outros, uma gênese brasileira. Adverte o ensaísta que seu estudo pretende mostrar que Bilac não é um poeta sem importância. Por outro lado, Suassuna não reivindica prioridades nacionais nem procura diminuir a originalidade do poeta português. Mas procura demonstrar, pela análise de textos dos dois poetas, que Bilac, antes de Fernando Pessoa, recriou "miticamente a história marítima portuguesa, levado, no seu tradicionalismo, pela verdadeira obsessão que sentia por Portugal". ${ }^{6}$

O poema "Sagres" data de 1898, tendo sido publicado em livro no ano de 1902. O mais antigo poema de Mensagem, coincidentemente dedicado a D. Henrique, é datado de 1913. Esclarece Ariano Suassuna:

4. BILAC. Poesias, p. 231-38.

5. SUASSUNA. Bilac e Fernando Pessoa; uma presença brasileira em Mensagem, p. 77-98.

6. SUASSUNA. Bilac e Fernando Pessoa; uma presença brasileira em Mensagem, p. 78 . 
Ora, em 1912, Bilac realizou um dos sonhos de sua vida, que era ir a Portugal; fez conferências e leu versos em Lisboa. Não tenho dados para afirmar que Fernando Pessoa - que então estava em Lisboa - tivesse ouvido o "Sagres" em alguma leitura pública ou lido o livro de Bilac, mas bem pode indicar o fato de ter o poeta português escrito seu primeiro poema nacional tradicionalista no ano que se seguiu à visita de Bilac à Lisboa.

Cumpre acrescentar, em favor da tese do ensaísta, que aquela viagem de 1912 não era a primeira que Bilac fazia à Europa. Seu sonho de conhecer Portugal realizou-se bem antes disso, em 1890, ano de sua primeira viagem, quando conhece Lisboa, Madrid, Londres, permanecendo nesta última cidade durante todo o mês de outubro daquele ano. Mas o lugar que mais o encanta nessa viagem é Paris, onde fica Bilac por mais tempo, além de conhecer outras cidades e países europeus, conforme declara seu biógrafo e crítico Fernando Jorge. ${ }^{7}$ Encantado com Paris, é daí que Olavo Bilac, naquele ano de 1890, faz o seu mais severo julgamento sobre o Brasil: "Confraria portuguesa que a generosidade dos povos persiste em chamar país civilizado".

Em Paris, Bilac frequenta a residência do escritor brasileiro Eduardo Prado, por cujo intermédio vem a conhecer vários outros escritores, dentre os quais Eça de Queirós, de quem se torna amigo tão íntimo, que passou a frequentar com assiduidade o sobrado residencial parisiense em que morava o romancista português. Por intermédio de Eça, informa Fernando Jorge que Bilac tem oportunidade de conhecer os principais nomes da literatura francesa da época.

Bilac e Eça projetaram escrever, de parceria, uma peça de teatro, um drama que seria composto em versos, a que intitularam "A última filha de D. Pedro o cru - Tragédia cor de sangue de boi”. Fernando Jorge registra vários textos em que Eça de Queirós confessa sua grande admiração por ouvir as leituras de Bilac, como também registra muitos depoimentos em que o poeta confessa verdadeira veneração pelo romancista português.

De Paris, onde teve oportunidade de conhecer Émile Zola, Maupassant, Verlaine, Leconte de Lisle e outros, a recordação mais grata trazida por Bilac terá sido a amizade de Eça de Queirós.

Se assim aconteceu na primeira viagem do poeta à Europa, estranhável seria supor que, posteriormente, em 1912, regressando Bilac a Lisboa e ali fazendo

7. JORGE. Vida e poesia de Olavo Bilac, p. 209. 
conferências e declamando versos, Fernando Pessoa, que ali se achava, deixasse de tomar conhecimento da presença do poeta brasileiro em sua terra.

Ratificando, pois, os argumentos históricos de Ariano Suassuna, acrescentemos, ainda, que data exatamente de 1912 aquela profecia de Fernando Pessoa a que já nos referimos e que é oportuno repetir: "E a nossa grande Raça partirá em busca de uma Índia nova, que não existe no espaço, em naus que são construídas daquilo de que os sonhos são feitos".

A interiorização da matéria épica no clima subjetivo do poeta português ocorre, portanto, exatamente no ano em que o poeta brasileiro está em Lisboa. Cumpre notar que a mesma interiorização subjetiva, a que se refere Jacinto do Prado Coelho, nasce primeiro no espírito de Olavo Bilac, como demonstra Ariano Suassuna, observando que um só poema de Mensagem data de 1913, sendo posteriores todos os demais, a maioria deles compostos de 1928 a 1934.

Analisando a temática do poema "Sagres" e do livro Mensagem, demonstra Suassuna que toda a ideia central do livro de Fernando Pessoa já se achava no poema de Bilac.

Nas Odes de Ricardo Reis, Ariano Suassuna vai focalizar os seguintes versos, escritos em 1914:

Anjos ou deuses, sempre nós tivemos

a visão perturbada de que acima

de nós, a compelir-nos,

agem outras presenças.

Seria o influxo divino dessas presenças que compele o homem para o cumprimento do dever. Quando se trata do herói, aquelas presenças vão conferirlhe dignidade real e divina, a que têm direito somente os heróis. Em abono dessa interpretação, o ensaísta transcreve os seguintes versos de Mensagem, onde D. Duarte declara:

Meu dever fez-me, como Deus ao mundo.

A regra de ser Rei almou meu ser, em dia e letra escrupuloso e fundo.

Firme em minha tristeza, tal vivi.

Cumpri contra o Destino o meu dever.

Inutilmente? Não, porque o cumpri. 
Suassuna mostra a seguir, no poema de Bilac, a mesma ideia: "os deuses impelindo o Herói a enfrentar o Destino e consolando-o da derrota inevitável com a ideia de que o sonho continuará e que o simples fato de ter lutado já é vitória". A vitória consiste também na sobrevivência do sonho, jamais derrotado acrescentaríamos - como se pode ver nesses versos de Bilac:

Vê como a noite está cheia

De vagas e sombras... Aqui,

Deuses pisaram a areia

Hoje pisada por ti.

Não verás, com o olhar em chama,

Abrir-se, no oceano azul,

O voo das naus do Gama,

De rostros feitos ao sul...

Que importa? Vivo e ofegando

No ofego das velas soltas,

Teu sonho estará cantando

À flor das águas revoltas.

Tanto o D. Henrique de Bilac como o D. Sebastião de Fernando Pessoa são portadores do mesmo "orgulho insensato".

Em Bilac:

Empedrado na teima e no orgulho insensato

É que o Sonho lhe traz dentro de um pensamento

A alma toda cativa...

Em Fernando Pessoa:

Louco, sim, louco, porque quis a grandeza

qual a sorte a não dá.

Observa Ariano Suassuna no poema de Bilac o aproveitamento poético feito do jogo das palavras Sagres e sagrado, enquanto o poema de Fernando 
Pessoa procura tirar o mesmo efeito poético de associação semelhante: Sagres e sagração.

Acrescenta o ensaísta, ao lado de vários outros confrontos, "que o grande feito português foi a ousadia de rasgar o véu de bruma do mar e decifrar o segredo". Mostra nos versos de Mensagem o aproveitamento dessa ideia:

A mão que ao Ocidente o véu rasgou,

Foi alma a Ciência e corpo a Ousadia

Da mão que desvendou.

Lê-se também em Bilac:

Ao largo, Ousado: o segredo

Espera, com ansiedade,

Alguém privado de medo

E provido de vontade...

Mensagem dá notícia daquelas sonhadas terras que

São ilhas afortunadas,

São terras sem ter lugar,

Onde o Rei mora esperando.

Mas, se vamos despertando,

Cala a voz, e há só o mar.

Essas ilhas não hão de ser outras senão as Terras da Fantasia, que já aparecem no poema de Bilac, cujos alexandrinos vêm dispostos pelo ensaísta em estrofes compostas por versos de seis sílabas, para acentuar ainda mais a semelhança. Veja-se:

Terras da Fantasia!

Ilhas Afortunadas,

Virgens, sob a meiguice

e a limpidez do céu,

Como ninfas, à flor,

das águas remansadas! 
- Pondo o rumo das naus

contra a noite horrorosa,

Quem sondara esse abismo

e rompera esse véu,

Ao finalizar seu confronto de textos, onde colhemos a amostragem apresentada, Ariano Suassuna conclui confessando:

...em meus ensaios, o Demônio da criação me tenta mais que a musa da Exegese.

Procurando condensar nesta ligeira análise os argumentos do ensaístacriador, quisemos demonstrar que Ariano Suassuna é, também, bom exegeta de textos poéticos, o que leva a analisar com sensibilidade, erudição e lucidez crítica os textos de Bilac e Fernando Pessoa, para concluir que no poema "Sagres" se encontra uma gênese de Mensagem. Bem antiga é a familiaridade de Suassuna com os textos de Fernando Pessoa, que o ensaísta confessa ter descoberto em 1948.

Evidentemente, não é apenas nos seus ensaios que Suassuna é tentado pelo "demônio da criação". Exemplo maior de tentação dessa natureza vamos encontrar no seu Romance d'A pedra do reino, cuja rica intertextualidade a Profa. Elizabeth Marinheiro explora em sua tese de Livre-Docência, transformada em livro em $1977^{8}$

A intertextualidade, porém, é preocupação do romancista desde 1966, conforme quisemos mostrar, pois daquele ano data seu referido ensaio. E o Romance d'A pedra do reino e o príncipe do sangue do vai-e-volta, escrito entre 1968/70, só aparece editado em 1971.

8. MARINHEIRO. A intertextualidade das formas simples. 


\title{
Brazilian suggestions to the author of Mensagem: a reading of Fernando Pessoa's poem
}

\begin{abstract}
This article is based on the premise that Portuguese Modernism and Brazilian Modernism are two distinct cultural moments. Before Fernando Pessoa's Mensagem became known in Brazil, Brazilian poetry already made contributions, at least in terms of themes, to the little but great book of the Portuguese poet. This article intends to demonstrate that Pessoa accepted the contribution that came to him through the poetry of Olavo Bilac, one of Brazil's greatest Parnassian poets. In order to do this, it reviews the 1966 intertextual confrontation by Ariano Suassuna. Moreover, this article intends to make known a precious essay in the field of comparative literature by the author of A pedra do Reino, so that he can be admired not only as a playwright and a novelist.
\end{abstract}

Keywords: Mensagem, Fernando Pessoa, Olavo Bilac, Ariano Suassuna.

$$
\text { Referências }
$$

BILAC, Olavo. Poesias. São Paulo: Ed. Paulo Azevedo (Livraria Francisco Alves), 1964 .

BRITO, Mário da Silva. História do modernismo brasileiro; antecedentes da Semana de Arte Moderna. Rio de Janeiro: Civilização Brasileira, 1964.

COELHO, Jacinto do Prado. Diversidade e unidade em Fernando Pessoa. Verbo. São Paulo: Ed. da USP, 1977.

JORGE, Fernando. Vida e poesia de Olavo Bilac. São Paulo: Liv. Exposição do Livro, (Edição Centenário), s. d.

MARINHEIRO, Elizabeth. A intertextualidade das formas simples; (aplicada ao romance d'A pedra do reino, de Ariano Suassuna). Rio de Janeiro: Gráfica Olímpica Ed., 1977.

MURICY, Andrade. Panorama do movimento simbolista brasileiro. Rio de Janeiro: INL, 1952. vol. I.

SUASSUNA, Ariano. Bilac e Fernando Pessoa; uma presença brasileira em Mensagem. Estudos Universitários, Recife, v. 1, p. 77-98, jan.-mar. 1966. 